and now he enjoys his ordinary diet, and is got quite stout and lusty. The face is, of course, much disfigured, yet not so much as may be imagined. The wounds of the face that have occurred and recovered during the war, have been almost incredible in their character, and would scarcely be believed by those who had not seen them. The power of articulation in this case is, of course, very much interfered with, from loss of palate.

CAsE v. Victor Marezimer, aged 23 years, a Russian prisoner, was wounded at the Redan. A minis bullet passed into the left thigh at the junction of the middle with the lower third behind the femur, passing between it and the hamstring muscles, and passing out on the inner side slightly below the level of its entrance. It then entered the right thigh a little below, taking the same course as through the left thigh, passing out about two inches above the popliteal space on the outer side of the right thigh.

The man must, evidently, been standing at "attention" when struck; and the person who fired must have been on slightly higher ground than himself, to account for the slanting direction which the ball took. This man recovered, without a single unpleasant symptom, and has been for some time acting as my groom, in which capacity I can vouch for his ability.

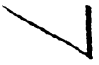

\section{CASES IN MIDWIFERT.}

By Thomas Radford, M.D., F.R.C.P.Edin., etc., Consulting Physician to St. Mary's Hospital, Manchester.

\section{[Continued from page 210.]}

CaSE XX. Jan. 7th, 1831. I was requested by Mr. to visit Mrs. L., from whom I received the following statement of the case up to the time I was called in. She was in the sixth month of her twelfth pregnancy, when she began to flood rather copiously whilst quietly sitting on a chair. She had several slight attacks at intervals of seven to ten days. Rest in the recumbent position, cool air, cold applications, and an acid mixture, with laudanum, were ordered. Notwithstanding she suffered from these repeated discharges of blood, she arrived at the end of the eighth month. On the evening of the above date, she had again a slight flow; but she had not been in bed above an hour before the bleeding became very profuse. She rose from bed, and stood leaning forwards over the edge of it, until she fainted, when she fortunately fell (forwards) on the bed.

Mr. - was now sent for; he found her somewhat recovered, although she still remained rather faint. Her pulse was very weak; her countenance was very pallid; the surface of her body felt coldish. The os uteri, he said, was placed rather low, and dilated to about the size of a whilling, but it was very firm. The hæmorrhage had been rery great, for the body and bed linen were completely saturated, and there was a large pool of blood on the floor; and therefore, although the organic state was unfavourable, as be considered it hazardous to risk another attack, he proposed immediate delivery; but she determinately refused to allow it.

At this time I was sent for. The discharge continued to slightly dribble. The os uteri was not more dilated than before mentioned, and was firm and undilatable. The placenta I distinctly felt. Under these circumstances, I did not feel warranted to acquiesce in the necessity and propriety of delivery; but I proposed to plug the vagina, and to apply an abdominal bandage, and a compress under it, over the uterus. A drachm of tincture of opium was administered. The discharge was now completely arrested. Brandy and water and suitable support were given. She was well watched for eight hours, during which time she improved, and had regular pains. The plug was now withdrawn, and along with it some coagula came 2 way, which was immediately followed by fresh blood. The os uteri was now considerably more dilated and dilatable; and as she consented to submit to delivery, I passed my hand (having had placed on a regulating bandage), and first separated a large portion of the placenta (which was centrally placed over the os), and then ruptured the membranes. I readily seized a foot, by which I brought the child's hips to bear on the os uteri, when I rested, and afterwards, as there was now no bleeding, I slowly extracted the body and head, cooperating in my efforts with the pains. The child was dead, and extremely white, as if it had also been drained of its blood. The placenta, being loose in the vagina, was immediately removed; its organisation was a good deal broken up. There was only an ordinary discharge. A drachm of tincture of opium was administered. She continued to go on favourably for the first three days, at the end of which time she had a shivering, succeeded by febrile heat. She felt pain in the hypogastric region, which was tender on pressure; and her right lower limb felt stiff, and began to swell; it was very pale; terminating in a slight attack of "phlegmasia dolens". Saline and suitable aperient medicines were preseribed. Leeches, poultices, and frictions, were applicd. She gradually recovered.

REMARKs. The blood which had run on the floor was, as far as possible, taken up, and the quantity was very great. Her loss in the aggregate must have been very considerable. She bore a larger loss than most pregnant women could have endured without nearly completely exhausting their vital powers. It is, however, a fact, that every woman in this condition bears loss of blood much better than at other times. It was perhaps a fortunate, although not a very courteous determination, that she refused the proposition of her medical attendant, for then the os uteri was not in a fit state for deivery to be safely performed; and it is not unlikely if this operation had been forcibly undertaken, her life might have been sacrificed. The plug answered well to secure her until the os uteri became sufficiently soft and open. The child doubt. less died from hæmorrhage. It was very white, and had a very different aspect from that which is observed in children who die in utero from other causes, or during extraction after turning, in cases of preternatural presentations.

CASE xxI. Sept. 29th, 1832. Mrs. O'Neil desired me to visit a hospital patiert, residing in Pump Street, who was flooding. She was in labour of her sixth child, but not quite at the end of pregnancy. During the seventh and eighth months, she had a slight attack of the same accident, both of which were easily arrested by rest in bed, and the external application of cold rinegar and water. She had pains for about three hours before I saw her, but they were now more frequent and stronger. The discharge, at first trivial, had become very profuse. She was rather pale, and felt a little faintish. Her pulse was more frequent than natural, but was not very weak. The os uteri was dilated to about the size of a crown-piece; it was soft and yielding. I ascertained that the placenta was placed over it, but I could not find its connexion with the membranes, and therefore I concluded that this organ was nearly (if not) centrally fixed over the os uteri. One drachm of tincture of opium was taken.

The local and general coudition being favourable for delivery, and the child being alive, I concluded to perform this operation, having first had the regulating bandage put on, so as just to support the uterus, but afterwards to be cautiously tightened, as required, during the passage of the child. I now passed my hand slowly on, in a conical form, to the os uteri, and endeavoured to find the separated portion of the placenta, which (as I thought) I did. In carrying my hand onward, I moved it sideways, in opposite directions, so as to detach a considerable and an adequate portion of this organ; during which there was an increased discharge of blood. Having ruptured the membranes, I easily found a foot of the child, and readily brought it down. After I had drawn it so far as to bring the breech 
of the child, with one thigh bent upon its abdomen, to lightly bear on the cervix and os uteri, I rested, so that theee portions of the uterus should not be too rapidly distended, before they were in some measure prepared for the paseage of a bulk of such magnitude. The hæmorrhage had nor ceased; and as the child had not adranced 80 far so to expose the funis to dangerous pressure, I raited awhile longer, during which time the bandage was kept woll tightened, and friction used over it, so as to induce nterine action. Shortly a strong pain occurred, when I cantiously drew down by the leg, and fortunately the child adranced; and as the pains continued, I cooperated in slowly extracting, and in the course of a very short time the child was born alive. The placenta followed immediately; on its maternal surface were to be seen the signs of the former and the more recent separations. There was no more bleeding. A drachm of laudanum was given. She went on very well until the third day, when she had a slight attack of phlebitis, which readily yielded to treatment.

REMARKs. Both the local and constitutional condition were highly favourable for delivery : I therefore at once had recourse to it. Although the os and cervix uteri'were tangibly in such a state of non-resistance to even a moderate force, yet I considered it both wiser and safer slowly and cautiously to draw down the child after having turned it. Its life, as well as that of the mother, would have been hazarded by too rapid extraction. The breech, with one thigh bent upwards and lying on the child's belly, is (as I have elsewhere stated) nearly equal in its measurement to the head; so that if this part is rapidly pulled through the cervix and os uteri before these portions of the uterus are prepared (which preparation must be gradually effected to permit its safe passage), this forcible distension then produces laceration and contusion of these parts, which in some cases has been found nearly in a state of sphacelus. Phlebitis and peritonitis not unfrequently occur after this mischievous practice.

CABE XXII. I am indebted to my respected friend and colleague, Mr. Masfen, for the following case, in whose words it is cited :-

"About 8 o'clock on the evening of Feb. 5th, 1856, I was called in by Mr. Harris, to visit Mrs. N., of Silver Street, Hulme, who was stated to be eight mouths pregnant, but who had been in labour for two days, and was flooding considerably. On my arrival, I found her looking extremely pale, with feeble pulse of about 80 , and was told she had lost a great deal of blood, but the hæmorrhage had ceased; she had had two half drachms of laudanum, and described herself as tolerably comfortable. I ascertained a placental presentation, with the os uteri dilated to the size of a shilling, and there were moderate uterine pains. I gave her a drachm of laudanum, but as it did not appear to have any sedative action upon the uterus, I thought it desirable to hasten the delivery, and plug the vagina till such time as the os should be sufficiently dilated. I accordingly introduced a large oval sponge with some diffculty into the ragina, pressed it firmly against the os uteri, and secured it by a $\mathrm{T}$ bandage. I ordered four half drachms of powdered ergot to be given at intervals of half an hour ; and having given directions to be sent for, if the slightest hæmorrhage should occur, or as soon as there had been sufficient action to produce dilatation of the 08, I left the house. I was not summoned again till $100^{\circ}$ clock the next morning, when Mrs. Harris informed me that the ergot had produced no apparent effect, that the pains had continued slightly through the night, that there had been no hæmorrhage; but that on removing the bandage this morning, the sponge had come away, and she had immediately sent for me. I found the patient much in the same condition as I had left her, with feeble pulse, and deadly pallor of countenance. I gave a drachm of laudanum, and the os having been fully dilated, proceeded to deliver by turning. This was effected in a fer minutes without any difficulty, and I ruptured the membranes after I had found the foot. The introduction of the hand appeared to give her considerable pain. The placents came aray in fre minutes after the birth of the child, and the uterus contracted firmly. At the edge of the placents, the portion which had been detached was essily distinguishable, sbout the size of the longitudinal section of a lemon, and on its centre was a darker coloured prominence, about the size of a walnut, produced by the long continued pressure of the os. There was no hæmorrhage. I applied a binder myself tightly over the abdomen; and the patient expressed herself as feeling very comfortable, and much delighted at having got it over so easily. The pulse at this time was scarcely perceptible, but it materially improved under the influence of a drachm of laudanum, which I ordered to be repeated. I remained in the house half an hour after the delivery, and she thought she should go to sleep, but eomplained of the tightness of the binder. It however was not slackened. On reaching home, about an hour afterwards, I found an urgent message had been left some time before, that I should visit the same patient immediately. I lost no time, but found that all was over. It appears that within fire minutes of my leaving the house, she was suddenly seized with symptoms of dissolution. $A$ neighbouring medical man was called in, but he said nothing was to be done, and she did not live many minutes. There had been no more hrmorrhage; and the uterus, which I examined, was still firmly contracted.

"This case presents two points worthy of consideration. Would different treatment, or would additional treatment, have been attended with a satisfactory result ? As regards the propriety of delivering under such circumstances, my friend Dr. Radford, I believe, entertains doubts. It appeared to me, however, that to leave the patient with symptoms of labour, and an ascertained placenta previa, would have been attended with imminent danger; and to have stayed an indefinite time, would have been out of the question, as actual labour might not have come on without interference for days or weeks. For loss of blood simply, I have almost invariably found opium a specific; and the quantities of this drug, which exsanguined patients will tolerate, is only limited by the exient to which the hæmorrhage has proceeded. The patient had half an ounce of laudanum in fifteen hours; she would doubtless have borne much more, but the symptoms did not appear to require it. The most direct and rational remedy-and, I think, the best-for extreme loss of blood, is transfusion. I performed this operation a few years ago in a somewhat similar case (vide Lancet, 1851, vol. i, p. 434), with perfect success. The gradual return of the pulse as the process was going on, at first wavering, then permanent, and afterwards the return of consciousners and the manifestation of interest in what was going on, establish this as a remedy of the highest utility. But what is the indication for it: necessity? The patient on whom I performed the operation was apparently lifeless, utterly unconscious, and with no pulse at the wrist. In this case, the patient, when I left her, was lively and cheerful, and the pulse was improving under the use of opium. Dr. Radford speaks highly of the use of galvanism, and thinks it might have been advantageous in this case. Of this remedy, I have no expcrience; but one serious objection to either of these latter plans, in poor, not being hospital practice, is the difficulty of obtaining in time the proper instruments and efficient assistants."

CLSE XXIII. Two cases were communicated to me by a medical friend, to be used as I thought proper; and as one (the following) illustrates an error of practice, I shall relate it in his own words :-

"About midnight, December 1st, 1840, I was sent for to Mrs. M. N. I. I was informed on my arrival, that she had been flooding a considerable time, and had lost a large quantity of blood, which seemed to be true, from the state of exhaustion the poor creature was in; for her faintness was extreme, and she had every symptom of the most immediate danger. Upon examination, I found the os uteri a little dilated, and the placenta evidently presenting; but there had been little or no pain or uterine con- 
traction. Hering waited about an hour, during which time I tried to irritate the uterus with $\mathrm{my}$ finger so as to induce vigorous action, I obtained the desired effect of increasing the pains, and dilating the os uteri to its fullest extent, although I at the same time also increaced the heomorrhage. I now resolved to give her the chance of an immediate delivery, which I effected, by introducing my hand into the uterus, and turning and bringing away the foetus; and this I did with greater facility than I could hare imagined, as the resistance from the uterus was very trifling. I endearoured to pass my hand through the placenta, but not being able to do it, I separated it on one side, until there was sufficient room for my hand to pass.

"Immediately after the birth of the child, which was dead, I detached the placenta, the uterus having but little power to expel it; and apprehensive, by its detention, of the risk of further hremorrhage from its extensive separation. The woman remained very faint and weak a long time after delivery; but being carefully nursed, she recovered by degrees, and was able to go out by the end of six weeks."

RExarks. Great hazards were run by the injudicions interference with the os for the purpose of inducing uterine action. This practice was calculated to induce irregular contraction of the uterus, to produce a further separation of the placenta, and thereby an increase of flooding. The unsuccessful attempt to pass the hand through the placenta was, no doubt (and might have been still more), mischievous. We cannot positively say that the death of the child was caused by this procedure; but most assuredly its chances of being born alive were considerably lessened by it, as the tissue of the placenta must have been more or less injured by trying to perforate this organ.

\section{[To be continued.]}

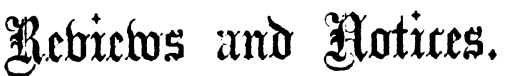

A Marual op Zooloax. By M. Mrune-Edwards, Member of the Institute. Adopted by the Council of Public Instruction of France. Translated by R. Krox, M.D., F.R.S.E. Illustrated by 500 first-class Engravings. London: Henry Reushaw.

WE have rarely examined a work calculated to impart scientific knowledge in a popular manner with so much pleasure as this excellent French manual, which Dr. Krox has presented to the public in an English dress. One of the most difficult things to do in literature is to put a train of scientific thought in plain and intelligible language, so that he who runs may read, not reluctantly, but pleasurably. The fault of most popular manuals on scientific subjects is, that they drag science down to the comprehen. sion of the meanest capacity, rather than deal with as much of it as can really be rendered agreeably intelligible, at the same time imparting so much interest to that which is accomplished as to render the reader anxious to obtain a profounder information. The first method tends to degrade science, and to render the reader conceited; the second to open a vista to the student, which leads him imperceptibly forward, at the same time that it shows him how much he has to learn.

Zoology is indeed a splendid theme, embracing, in its widest meaning, the chain of animated life, from man, capable of the splendid generalisation of a Curier or a Newton, down to the zoophyte moored to some submerged rock, whose life differs but little from the torpid condition of a vegetable. Upon the different portions of this vast chain the mamual before us touches; and link by link, anatomically and phyoiologically, it is examined, and shown to the oye of the reader by means of the beautiful woodcuts which co profusely illustrate the work. Dr. Knox,
Whose knowledge of anatomy, comparative and otherwise, all modical men will so readily acknowledge, has enrichod the pages of M. Milne-Edwards by numerous notes, gathered from his own researches; whilst he has been enabled, by his profound knowledge of the subject, to curtail without impoverishing, and to render intelligible without altering the meaning of his text. We believe this work will take a high place in England, as it does in France, as a work of primary instruction upon a subject which is congenial, we think, to the national mind; and we can imagine the pleasure with which many a village White, or Waterton, will read a volume which gives so comprehensive a view of a science which he studies in the limited sphere of his own neighbourhood.

The medical man proceeding to our Indian dependencies, in the service of the Company, should most certainly contain this admirable volume in his kit, as it will refresh his mind upon the leading points of a subject which be will most probably have such splendid fields for pursuing, and to which, indeed, his attention is especially directed by his munificent masters. To the great public, who wish to fix in their minds the rough sketch, if we may so term it, of natural history, this volume of five hundred pages will prove an invaluable instructor, and, we masy add, one of the cheapest in the history of well printed and well illustrated scientific literature.

Trroat Aimyerts, more espectalet the EnLaraed TonSILS AND ELONGATED UVOLA, IN CONNEXION WITH Defects of Voice, Speech, Hearina, Dealotition, Respikation, Covgh, Nasal Obstruction, and tho IYPERFECT DEVELOPMENT OF HEALTH, STRENGTH, AND Growte, in Youna Persons. By James Yaarsher, M.R.C.S. Sixth edition. London: John Churchill. 1856.

We think Mr. YearsueY has done excellent service by the earnest manner in which he has so long dwelt upon the bearing which morbid conditions of the throat have upon the organs of speech, voice, and hearing. The important part which the mucous passages perform in the exercise of these organs had not certainly been pointed out with such force before this work was first published. The insignificant operations of excising the tonsils and catheterising the Eustachian tube bave, without doubt, removed in and we think Mr. Yearsley has done great good by his constant adrocacy of these measures. It has indeed been urged against the former operation, that it is needless, and indeed injurious, inasmuch as it deprives the patient of the very nocessary back-curtain of the mouth. This observation would be perfectly true if made with reference to the healthy tonsils and uvula, but is totally incorrect when applied to their morbid conditions. Those only who have had their attention drawn to the subject can well estimate the perpetual discomfort, which in some cases amounts to actual misery, of elongated uvula, lolling upon the tongue, and causing a constant teazing cough; or the still more disagreeable effects of enlarged tonsils, which, in some cases, impede respiration to a deyree highly injurious to a proper aeration of the blood. The effects of an hypertrophied condition of the mucous membrane in the Eustachian tube, on the faculty of hearing, may be well imagined. The author gives plates in this work, in order to enable those suffering from deafness from this cause to use the catheter and syringe, in order to clean the passage. Mr. Yearsley remarks with truth that the only effectual way to gargle the throat is through the Eustachian tube. But fer individuals, we fancy, would like to resort to this instrument for such a purpose; but the medical man might take the hint with advantage in all cases where it is necessary to relieve urgent distress, caused by an inflamed condition of the back of the throat. 